\title{
THE COVID-19 PANDEMIC AND THE MENTAL HEALTH OF STUDENTS
}

\author{
Madona Kekelia, \\ Doctor of Psychology, Professor, \\ Georgian National University SEU \\ Eliso Kereselidze, \\ Doctor of Psychology, Professor, \\ Georgian National University SEU \\ Ina Shanava, \\ Doctor of Social Sciences, Associate Professor, \\ Georgian National University SEU
}

\begin{abstract}
The disease COVID-19, caused by the new coronavirus (SARS-CoV-2), was first detected in Wuhan, China in late December 2019, and, due to its high degree of virulence, it has spread rapidly around the world ever since. On March 11, 2020, the World Health Organization descried the situation as a pandemic, and in March 2020, a state of emergency was declared in Georgia. To limit the spread of the virus "lockdown" was ordered and, except in emergencies, the population was restricted from leaving home, the learning process in educational institutions was suspended, and all sorts of gatherings and public transport were put off. In these circumstances, as well as the risks associated with deteriorating health and economic problems, students also found themselves in a difficult situation in terms of getting access to education, caused by the transition to distance learning.

The social category of students is characterized by an active lifestyle, a wide range of relationships and contacts. In consequence of the social distancing policies and measures implemented across the country to slow the spread of the virus, the reduction in contacts has given rise to feelings of loneliness and depression. The entire situation is likely to negatively affect the psychological well-being of students. It has been proven that high levels of stress among students are associated with low mental wellness, which in turn, may lead to poor academic performance and the emergence of social and psychological problems ${ }^{1}$. Based on the abovestated, the aim of the present paper was to establish a link between the indicators of loneliness, depression and psychological well-being with students in the context of constraints caused by the COVID pandemic. Patient Health Questionnaire (PHQ-4), Loneliness Scale (UCLA) and Psychological Well-Being Scale (PWBS) were used for the purpose. Analysis of the results revealed that depression, anxiety and loneliness have a negative bearing on psychological well-being. The differences were analyzed in obedience to demographic characteristics.
\end{abstract}

Keywords: Mental Health, Loneliness, Depression, Psychological well-being.

\footnotetext{
${ }^{1}$ S. Akhter, "Psychological Well-Being in Student of Gender Difference". The International Journal of Indian Psychology Volume 2, Issue 4,2015.

T. Munir, S. Shafiq, Z. Ahmad, S. Khan, "Impact of Loneliness and Academic Stress on Psychological Well Being among College Students”. Academic Research International Vol. 6(2) March 2015.
} 


\section{Introduction}

With respect to the COVID pandemic, the issues related to psychological well-being are principally relevant for the modern world. In the changed realities, the problems created by the pandemic lead to an increase in the rates of stress, anxiety and depression in society, which may become the determinant of pessimistic attitudes towards life, reduced self-confidence, losing optimism, as well as changing life goals and values.

Interest in psychological well-being and spiritual health peaked in the period from the late 1950s to the 1970s. Psychological well-being refers to the feeling of happiness, life satisfaction and successful coping with stressful situations by a person ${ }^{2}$.

Psychological well-being can be viewed from a cognitive and emotional point of view, which implies a positive assessment of one's own social life, condition and relationships. Cognitive assessment refers to the degree to which a person is satisfied with their life conditions. The affective aspect is primarily based on feelings and reflects on how often a person experiences happiness and sadness. This assessment is based on the assumption that people attach great importance to good and bad, and hence, they also value their own lives either as good or bad. ${ }^{3}$

It should be noted that in addition to social life satisfaction, demographic and life aspects may also have an impact on psychological well-being even if it is driven by the achievement of one's own goal.

For the past two decades, the Ryff Scales have been used in empirical studies. Studies included issues related to work, mobility, personality, well-being, and the ability of gifted students to realize their potential. In addition, the Ryff's Model was used to study the degree of depression, value system, and perfectionism among college students ${ }^{4}$.

Student psychological well-being is a central concern of research. Under the conditions of social isolation and prohibitions, along with psychosocial problems, the change in the format of teaching in the educational system (switching to distance learning) and the restriction of social relations also proved to be painful for students. Continuing to study at the university for a young person involves the search for his/her individuality, accomplishment, new and interesting social relationships, and self-sustenance.

In social isolation driven by the pandemic circumstances, limited emotional and social support can trigger feelings of loneliness and depression. It is well known that students, experiencing loneliness, suffer from an inferiority complex and low self-efficacy. Low levels of self-esteem include negative assessments of one's own health, appearance, behavior, and functioning. The student's depressed mood hinders his/her academic achievement, as it causes difficulty concentrating, low self-esteem, and a decrease in the feeling of pleasure in doing something that once used to be fun for him/her ${ }^{5}$.

Loneliness is a condition that affects people of all ages. It is a subjectively perceived negative feeling associated with a lack of social relationships. The feeling of loneliness is related to the assessment of a person's overall level of social interaction. Its rate indicates how much the real quality and quantity of social relations lags behind the desired. The feeling of loneliness can be a reaction to the lack of social relationships that are important to a person, the low quality of social relationships, or the lack of sincere and emotional relationships.

${ }^{2}$ R. K. Bhagchandani, Effect of Loneliness on the Psychological Well-Being of College Students, International Journal of Social Science and Humanity, Vol. 7, No. 1, January 2017.

${ }^{3}$ S. Akhter, Psychological Well-Being in Student of Gender Difference. The International Journal of Indian Psychology Volume 2, Issue 4,2015.

${ }^{4}$ See footnote 3 .

${ }^{5}$ A. Rahman, A. Bairagi, B. Kumar Dey \& L. Nahar. "Loneliness and depression of university students". The Chittagong University J. of Biological Science, vol-7 (1\&2), 2012, 175-189. 
Interacting with the social environment is vital for a person. The isolation imposed during a pandemic gives rise to and exacerbates feelings of loneliness. ${ }^{6}$

According to the most common definition of loneliness, it is the feeling caused by the difference between ideal and real social relationships. Definitions of the feeling of loneliness describe it as a state of loneliness or being alone. The feeling of loneliness is, in essence, a mentality. Owning to it, a person feels spiritually empty, lonely, and unwanted by others. Individuals who are lonely often feel the need to make contact with other people, prevented by their mentality. Loneliness has always been considered a widespread problem for older people, but, today, high levels of loneliness are also observed among youngsters as well. Loneliness is a subjective experience, connoting that if a person thinks he/she is alone, he/she also feels lonely likewise. It should be noted that not everyone who is alone will necessarily experience loneliness. ${ }^{7}$

Loneliness and social isolation can catalyze many mental problems, including severe stress disorders, irritability, insomnia, emotional disorders, mood swings, depressive symptoms, fear and panic, anxiety, frustration, loneliness, self-harm, suicide, and drug addiction. Some people enjoy being alone. According to Tillich (Tillich, 1959), "being alone reflects the beauty of solitude, while loneliness reflects the pain of feeling alone". Larson (Larson, 1997), in describing the difference between being alone and loneliness, explained that "feeling lonely" should be easily distinguished from other concepts, and "being alone" means that a person independently made such a choice ${ }^{8}$.

\section{Method}

Aim of the study: To establish a link between the rates of loneliness, depression and psychological well-being among students in relation to the COVID-19 pandemic-induced restrictions. Patient Health Questionnaire (PHQ-4), Loneliness Scale (UCLA) and Psychological Well-Being Scale (PWB) were used for the purpose. The survey participants rated the provisions by scoring on the scales. SPSS 20 was used for data processing.

Target group: Students.

Selection: Non-random sampling methods were used: available selection and focus groups.

\subsection{Participants}

462 students $(87.7 \%$ female and $12.3 \%$ male) of Georgian National University SEU participated in the survey. $90 \%$ of the survey participants were single, $9.6 \%$ were married and $0.4 \%$ was divorced. $89.6 \%$ of respondents lived with family, $6.3 \%$ lived alone, and $-4.1 \%$ lived with relatives. According to $69.8 \%$ of the students surveyed, they did not have their own income, while $30.2 \%$ showed the opposite results. $88.3 \%$ of the students surveyed rate their family's economic situation as average, $9.1 \%$ as low, and $2.6 \%$ as high. $49.9 \%$ of the surveyed students were freshman students, $29.8 \%$ were sophomores, $10.9 \%$ were juniors, and $9.4 \%$ were senior students. $20.6 \%$ of the surveyed students evaluated their academic success with 70 points, $19.5 \%$ with 50 points, $16.2 \%$ with 80 points, $14.8 \%$ with 60 points, $10.8 \%$ with 90 points, $6.6 \%$ with 40 points, $4.2 \%$ with 100 points, $2.9 \%$ with 30 points, $2.2 \%$ with 10 points, $1.8 \%$ with 20 points, and $0.4 \%$ with 0 points.

\footnotetext{
${ }^{6}$ R. K. Bhagchandani, , Effect of Loneliness on the Psychological Well-Being of College Students“, International Journal of Social Science and Humanity, Vol. 7, No. 1, January 2017.

${ }^{7}$ See footnote 6 .

${ }^{8}$ R.K. Bhagchandani, "Effect of Loneliness on the Psychological Well-Being of College Students, International Journal of Social Science and Humanity", Vol. 7, No. 1, January 2017.
} 


\subsection{Data Collection Procedure}

Using the Google Drive platform, it has become possible to extract survey data. Respondents participated in the survey voluntarily. Anonymity was maintained. In order to get complete information, answering all the questions was mandatory.

\subsection{Research Limitation}

The main drawback of the survey is the limitation related to the selection of respondents. It would be better if the students of other HEIs in Georgia were also involved in the research. The restriction is also related to the violation of gender balance, according to which the vast majority of respondents were female.

\section{Tools}

\subsection{Patient Health Questionnaire}

The Patient Health Questionnaire (PHQ-4) ${ }^{9}$ consists of 4 provisions and is evaluated by scoring points for the provisions on the four-point Likert scale (1- hardly any; 2 - a few days; 3 - for most days; 4 - almost daily). The instrument allows to be used to measure depression (PHQ-2) and anxiety (GAD-2) on a two-point scale. The evaluation is determined by the total number of points assigned to all four provisions. Scores are rated as normal (0-2), light (3-5), medium (6-8), and severe (9-12). If the first two questions score a total of $\geq 3$ points, it indicates an anxiety rate, and if the second two questions score a total of $\geq 3$ points, depression is likely. It should be noted that the scale is an abbreviated version of problem identification that is not used to diagnose depression and anxiety.

\subsection{Psychological Well-Being Scale}

The Psychological Well-Being Scale (PWB) ${ }^{10}$ consists of 8 provisions and describes important aspects of an individual's functioning, including healthy social relationships, a sense of competence and the key meaning of life and goals. Each provision is rated on a seven-point scale ( $1=$ strongly disagree; $2=$ disagree; $3=$ partially disagree; $4=$ agree to disagree; $5=$ partially agree; $6=$ agree; $7=$ strongly agree). All provisions reflect a positive attitude. Points can range from 8 points (I strongly disagree with any of the provisions) to 56 points (I strongly agree with all the provisions). The high score obtained indicates the positive attitudes of the respondents towards different areas of functioning. Although this tool does not explore individual aspects of psychological well-being individually, the focus is on relationships about positive functioning in different areas.

\subsection{Loneliness Scale (University of California, Los Angeles)}

Loneliness Scale (University of California, Los Angeles UCLA) is a three-provision scale, and each provision is evaluated on a three-provision scale: $(1=$ rarely; 2 = occasionally; 3 = frequent $)$. The instrument measures

${ }^{9}$ K. Kroenke, R. L Spitzer, J. T BW Williams, L. B. Löwe. “An ultra-brief screening scale for anxiety and depression: the PHQ-4”. Psychosomatics 2009; 50:613-621.

Occupational Medicine, "Patient Health Questionnaire-4”, QUESTIONNAIRE REVIEW. 2016.

${ }^{10}$ Ed Diener, D. Wirtz, R. Biswas-Diener, W. Tov, Chu Kim-Prieto, Dong-won Choi, and S. Oishi, "New measures of well-being: Flourishing and Positive and Negative Feelings". C Springer Science+Business Media B.V. 2009. 
three aspects: social relationships, relationships, and self-reported relationships. If the total number of points on the scale for the regulations is high, it indicates a high rate of loneliness, while a low score indicates a low rate of loneliness.

\section{Description of Results}

For the purpose of the research, respondents' rates of depression and anxiety were to be assessed on a patient health survey scale. A two-dimensional analysis revealed that $31.8 \%$ of respondents had a normal rate of depression and anxiety, $37.9 \%$ had a mild rate, $17.7 \%$ had a moderate rate, and $12.6 \%$ had a severe rate. Differences on this scale were identified according to gender characteristics, namely, $28 \%$ of females and $25 \%$ of males experience depression and anxiety. In married respondents, the rate of depression and anxiety is higher $(27 \%)$ than in married (26\%) and divorced (22\%) students.

Statistically significant differences were found in line with the economic status of the family, according to which, based on one-dimensional analysis, it was found that the lower the economic status of the family, the higher the rate of depression and anxiety $(\mathrm{P}=0.000<0.05)$. In those respondents with low family economic situation, the rate of anxiety and depression is high (36\%). Depression is manifested in $26 \%$ of respondents who rate the economic situation of the family as average and $30 \%$ who rate it as high. The analysis of the results revealed that $27 \%$ of students living with family, $32 \%$ of students living alone and $32 \%$ of students living with relatives have depression and anxiety. Depression is manifested in $30 \%$ of students who have their own income and in $26 \%$ of those with no their own income.

The processing of the results revealed that the differences identified in keeping with the level of learning on the Patient Health Scale were statistically reliable. In particular, with the increase in the level of learning, there is a growing trend of depression among students. Depression and anxiety were reported in $23 \%$ of freshmen, $32 \%$ of sophomores, $31 \%$ of juniors, and $31 \%$ of seniors. The relationship between academic achievement and depression rate was found to be statistically significant, with the higher the depression rate, the lower the students' own success rate $(50 \%)$, and the lower the depression rate, the higher the students' own academic success rate $(12 \%)$. , $\mathrm{P}=0.000<0.05$.

A two-dimensional analysis was used to process the data obtained on the Loneliness Study Scale, which showed that $52.8 \%$ of the respondents had a low, 30.3\% average, and $16.9 \%$ high on the Loneliness Study Scale. Scale differences were also identified by gender, with $27 \%$ of female respondents and $24 \%$ of male respondents experiencing loneliness. According to marital status, $33 \%$ of divorced respondents, $28 \%$ of married respondents and $19 \%$ of married respondents experience loneliness.

Based on the data processing, differences were found on the Loneliness Study Scale according to the economic status of the family, according to which the lower the students assess the economic status of the family, the higher the feeling of loneliness among them and vice versa. In particular, $33 \%$ of students, who rate their family economic status as low, experience loneliness. $26 \%$ of students, who rate family economic status as average experience, loneliness and $21 \%$ of students experience loneliness who rate family economic status as high. $30 \%$ of students who have their own income experience loneliness, while $25 \%$ of students who state that they do not have their own income indicate loneliness.

Statistically significant differences were found on the loneliness scale according to the learning level $\mathrm{P}=0.000$ $<0.05$. The lower the level of the student, the less he/she experiences loneliness, namely, $24 \%$ of freshmen experience loneliness, $31 \%$ of sophomores, $28 \%$ of juniors and $29 \%$ of seniors. Students living alone (26\%) are less likely to experience loneliness than students living with family (30\%) or relatives (32\%). Differences were found between students' assessment of their own academic success and feelings of loneliness. The higher 
the feeling of loneliness, the lower the students' assessment of their own success (61\%), while the lower the loneliness rate, the higher the students' assessment of their own academic success (16\%).

Processing the data obtained from the study and two-dimensional analysis revealed that $2.2 \%$ of the surveyed students have low psychological well-being, $48.1 \%$ of them indicate average and $49.8 \%$ show high rates.

Based on one-dimensional analysis, it was found that the rate of psychological well-being was higher in female respondents (63\%) than in male respondents (60\%). 68\% of married respondents experience more psychological well-being than single (62\%) and divorced respondents $(57 \%)$. Interesting results are revealed in agreement with the level of learning on this scale, according to which statistically significant differences in psychological well-being were not revealed among the respondents of all four levels of education (freshmen $63 \%$, sophomores - $63 \%$, juniors - $63 \%$, seniors - $62 \%$ ).

Psychological well-being rates are lower for students who rated their family economic status as low (60\%) than for those students who rated it as average (63\%) and high (67\%). $62 \%$ of students with income indicate psychological well-being, in contrast to students who do not have their own income (63\%). Psychological well-being is higher for students living with family (63\%) and relatives (63\%), as opposed to students living alone (59\%).

Statistically significant differences in the Psychological Well-Being Scale were found in terms of academic achievement, with students who rated their academic achievement with low scores, experiencing lower psychological well-being (55\%) and students who rated their own academic achievement with high scores as well as high-achieving psychological rate (70\%).

Diagram N1: Differences in the Scale of Patient Health, Loneliness, and Psychological Well-Being by Demographic Characteristics.

\begin{tabular}{rlrllllll} 
N & \multicolumn{2}{c}{ Depression / Anxiety } & & \multicolumn{2}{c}{ Loneliness } & & \multicolumn{2}{c}{$\begin{array}{l}\text { Psychological } \\
\text { Well-Being }\end{array}$} \\
462 & M & SD & P & M & SD & P & M & SD
\end{tabular}

$\operatorname{Sex} \mathbf{n}(\%)$

$\begin{array}{lccccccccc}\text { Female } & 405 & , 28 & , 18 & & , 27 & , 20 & & , 63 & , 12 \\ \text { Male } & & & & \underline{, 35} & & & \underline{, 32} & & \\ & 57 & , 25 & , 21 & & , 24 & & , 60 & , 14\end{array}$

Age M(SD)

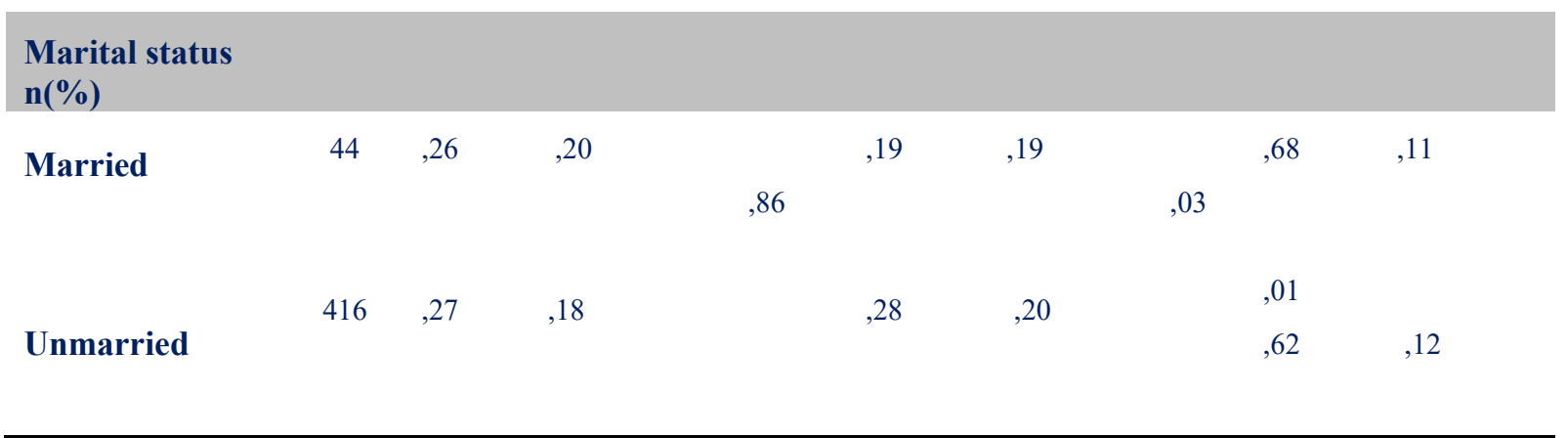


MADONA KEKELIA, ELISO KERESELIDZE, INA SHANAVA

\begin{tabular}{|c|c|c|c|c|c|c|c|c|c|}
\hline Divorced & 2 &, 22 &, 22 & &, 33 &, 31 & &, 57 &, 18 \\
\hline $\begin{array}{l}\text { Family } \\
\text { economic status }\end{array}$ & & & & & & & & & \\
\hline Low & 42 & ,36 &, 16 & &, 33 & ,20 & & ,60 &, 13 \\
\hline Medium & 408 & ,26 &, 18 &, 00 & ,26 & ,20 & ,08 & $\begin{array}{l}, 18 \\
, 63\end{array}$ & 12 \\
\hline High & 12 &, 30 &, 24 & &, 21 & ,22 & & 67 & , 17 \\
\hline $\begin{array}{l}\text { Level of higher } \\
\text { education }\end{array}$ & & & & & & & & & \\
\hline $\begin{array}{l}\text { First year of } \\
\text { study }\end{array}$ & & ,23 &, 17 &, 00 & ,24 & ,19 &, 00 & ,63 &, 12 \\
\hline $\begin{array}{l}\text { Second year of } \\
\text { study }\end{array}$ & 230 & ,32 & , 19 & &, 31 &, 21 & & ,98 &, 13 \\
\hline $\begin{array}{l}\text { Third year of } \\
\text { study }\end{array}$ & 137 & ,31 &, 19 & & ,28 &, 19 & & ,62 & , 10 \\
\hline
\end{tabular}

Fourth year of $\quad 44$

study

Personal income

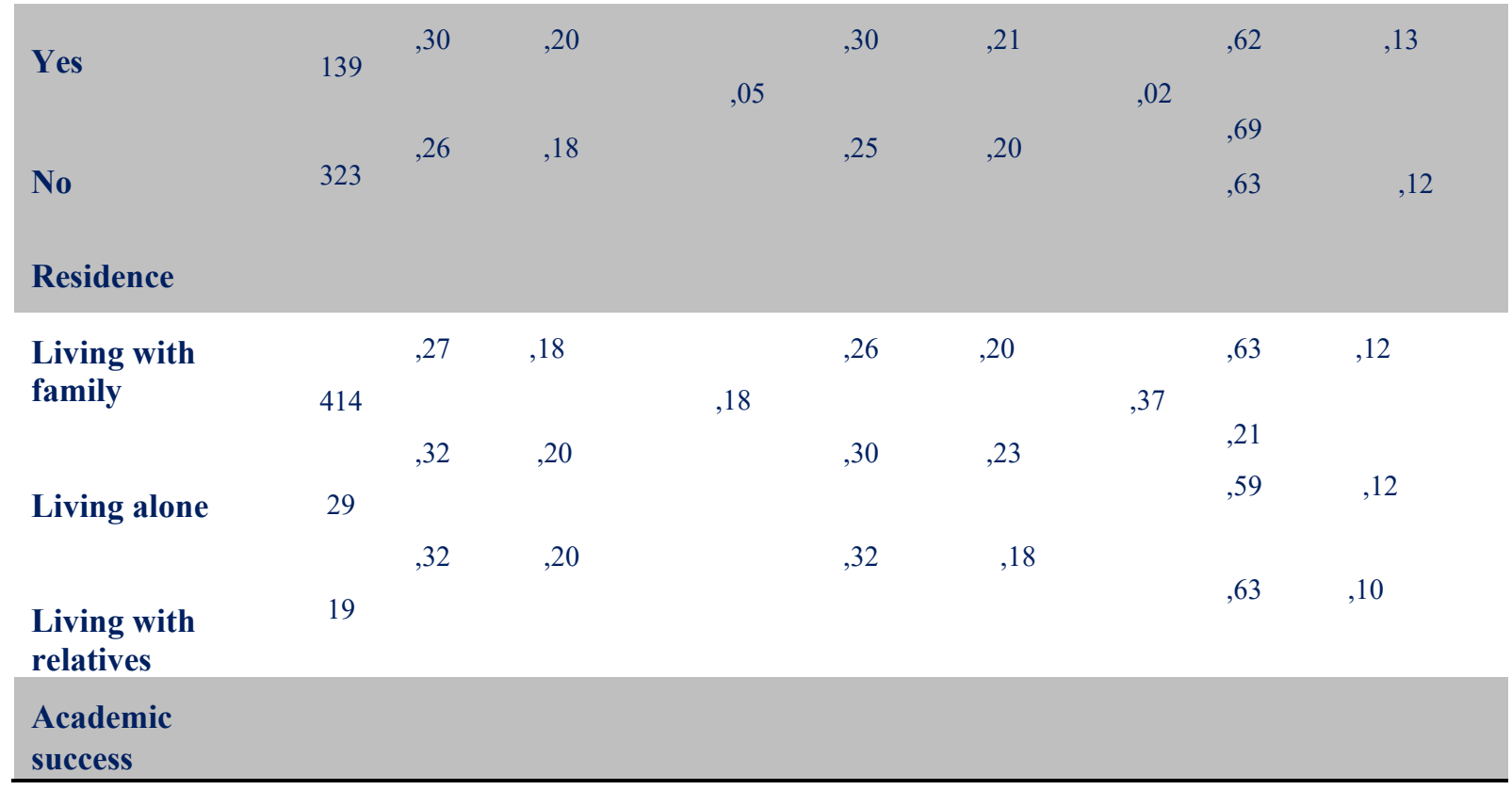




\begin{tabular}{|c|c|c|c|c|c|c|c|c|c|}
\hline 0-point & 2 &, 50 &, 18 & & ,61 &, 08 & &, 55 & 0,00 \\
\hline 10 - points & 10 & 34 &, 17 & &, 31 & ,21 & &, 56 & ,12 \\
\hline 20 - points & 8 &, 32 & ,21 & & ,29 & ,23 & &, 57 & ,12 \\
\hline 30 - points & 13 &, 34 &, 19 & &, 32 &, 17 & &, 57 &, 11 \\
\hline 40 - points & 30 & ,26 &, 17 & & ,26 &, 21 & & ,60 &, 11 \\
\hline 50 - noints & 88 &, 28 & ,19 & 0,00 &, 27 & ,20 & 0,11 & ,61 & ,12 \\
\hline 50 - points & 67 &, 32 &, 17 & &, 31 & ,20 & & 0,00 & \\
\hline 60 - points & 99 & ,26 &, 18 & &, 27 &, 21 & & ,60 &, 13 \\
\hline 70 - points & 77 &, 23 &, 17 & & ,25 & ,20 & & ,65 &, 10 \\
\hline 80 - points & 49 & ,28 & ,20 & & ,26 &, 21 & & ,65 &, 13 \\
\hline 90 - points & 19 &, 12 &, 12 & & ,16 &, 17 & &, 65 & ,13 \\
\hline 100 - points & & & & & & & &, 70 &, 10 \\
\hline
\end{tabular}

\subsection{Regression Analysis}

Regression analysis revealed that the Patient Health Scale explains $29.1 \%$ of the data variability $\left(\mathrm{R}^{2}, 085 ; \mathrm{R}^{2}\right.$ $\operatorname{Adj}=, 0,69 ; \mathrm{B}=, 473 ; \mathrm{ST}=, 177 ; \mathrm{T}=4,438 ; \mathrm{P}=000)$. The most important predictors on the study scale of patient health (depression and anxiety) were the economic status of the family, the presence of different levels of education and the assessment of their own academic success by the students. The Loneliness Scale reveals $26.8 \%$ of the data variability $\left(\mathrm{R}^{2}, 072, \mathrm{R}^{2} \mathrm{Adj}=, 055 \mathrm{~B}=, 486 ; \mathrm{ST}=, 199 ; \mathrm{T}=4,073 ; \mathrm{P}=, 000\right)$; having one's own income on the loneliness research scale, family economic status, marital status, being at different levels of education, and evaluating one's own academic success were revealed as statistically significant predictors. The Psychological Well-Being Scale explains $29 \%$ of the data variability $\left(\mathrm{R}^{2}, 084, \mathrm{R}^{2} \mathrm{Adj}=, 068 ; \mathrm{B}=, 518\right.$; $\mathrm{ST}=, 117 ; \mathrm{T}=7,368 ; \mathrm{P}=, 000)$, where marital status and evaluation of one's own academic success are important predictors.

\section{Diagram N2. Regression Analysis}

Patient Health

\section{Questionnaire (Depression / \\ Loneliness $\quad$ Psychological Well-Being} Anxiety)

\begin{tabular}{|c|c|c|c|c|c|c|c|c|c|c|c|c|c|c|}
\hline & B & SE & $\beta$ & $\mathbf{T}$ & B & SE & $\beta$ & $\mathbf{T}$ & $\mathbf{P}$ & B & & ${ }_{P}$ & $\beta$ & $\mathbf{T}$ \\
\hline - Sex & & 22,025 &,- 040 & -883 &,- 034 & ,029 &,- 055 & -1.198 & 231 &,- 024 & 017 &,- 064 & $-1,407$ & , 160 \\
\hline - Age & & 03,004 &,- 041 & $-, 726,468$ &,- 008 &, 005 &,- 091 & $-1,604$ & ,109 & ,001 & ,003 & ,021 & ,372 &, 710 \\
\hline $\begin{array}{l}\text { - Marital } \\
\text { status } \\
\text { n(\%) }\end{array}$ & ,033 & 029 & ,054 & $1,128,260$ & ,086 & ,033 & ,126 & 2,612 & ,009 &,- 052 & ,019 & -,129 & $-2,695$ & ,007 \\
\hline
\end{tabular}




\begin{tabular}{|c|c|c|c|c|c|c|c|c|c|c|c|c|c|c|}
\hline $\begin{array}{l}\text { Family } \\
\text { economic } \\
\text { status }\end{array}$ &,- 052 &, 025 &,- 095 & $-2,107 \quad 0,36$ &,- 053 &, 028 &,- 086 & $6-1,896$ & ,059 &, 020 &, 016 & ,055 & 1,210 & ,227 \\
\hline $\begin{array}{l}\text {-Level of } \\
\text { higher } \\
\text { education }\end{array}$ & ,039 &, 010 & ,206 & $3,721,000$ &, 035 & ,012 & ,167 & 2,994 & ,003 &,- 008 & ,007 &,- 061 & $-1,109$ & ,268 \\
\hline $\begin{array}{l}\text { Personal } \\
\text { income }\end{array}$ &, 24 &, 019 &, 061 & $1,287,199$ &, 043 &, 021 & ,096 & 2,025 &, 043 &,- 004 &, 012 &,- 015 &,- 323 & ,747 \\
\hline $\begin{array}{l}\text { Residenc } \\
\text { e }\end{array}$ & $-0,33$ &, 027 &,- 055 & $-1,212,226$ &,- 024 &, 031 &,- 035 &,- 770 & ,231 &, 012 & 0,18 & ,029 & ,640 &, 522 \\
\hline- & & & & & & & \multirow{2}{*}{\multicolumn{2}{|c|}{$-, 122-2,655$}} & & & & & & \\
\hline $\begin{array}{l}\text { Academic } \\
\text { success }\end{array}$ & \multicolumn{2}{|c|}{$-, 015,004$} & \multicolumn{2}{|c|}{$-, 165-3,633 \quad, 000$} &,- 012 &, 005 & & & ,008 &, 014 &, 003 & ,234 & 5,130 & ,000 \\
\hline
\end{tabular}

\subsection{Correlation}

Based on the data correlation analysis (Pearson Correlation Coefficient) it was found that the links between the patient's overall health indicators (depression / anxiety), loneliness and psychological well-being are significant (see Diagram N3).

- There is a strong positive correlation between depression / anxiety and loneliness $(\mathrm{r}=0.54, \mathrm{p}<.01)$

- Negative correlation between depression / anxiety and psychological well-being $(r=-0.35, p<.01)$

- Negative correlation between loneliness and psychological well-being $(r=-0.39, p<.01)$

\section{Diagram N3. Correlation between Patient Health (Depression / Anxiety), Loneliness and Psychological Well-Being}

\begin{tabular}{lccc} 
Depression & 1 &, 545 &,- 358 \\
Loneliness &, 545 & 1 &,- 390 \\
Psychological & & & \\
well-being &,- 358 &,- 390 & 1 \\
\hline
\end{tabular}

$* * \mathrm{p} \leq .01 ; * \mathrm{p} \leq .05 ; * * * \mathrm{p} \leq .001$

In order to check the reliability of the scales used in the study, the internal agreement coefficient - Cronbach's alpha coefficient was calculated for each scale. The strongest internal agreement was found on the patient health scale (depression / anxiety) ( $\alpha=, 80)$. Also, the scales of psychological well-being $(\alpha=, 79)$ and loneliness $(\alpha=, 78)$ have high internal consistency. (See Diagram N4)

\section{Diagram N4. Internal Agreement of Scales and Descriptive Statistics}




\begin{tabular}{|c|c|c|c|c|}
\hline & $\alpha$ & $\mathbf{N}$ & $\mathbf{M}$ & SD \\
\hline Depression &, 80 & 462 & ,272 &, 184 \\
\hline Loneliness & ,78 & 462 & ,268 & ,204 \\
\hline Psychological well-being & ,79 & 462 &, 627 & 121 \\
\hline
\end{tabular}

\subsection{Review of the Results}

In order to test the reliability of the scales used in the research, the internal agreement scores were calculated, according to which it was found that the agreement scores for each scale are high. It should be noted that based on the correlation analysis of the data, it was revealed that the connections between the scales used in the study are significant. Regression analysis revealed that the Patient Health Scale unfolds $29.1 \%$ of the data variability, the Loneliness Scale reveals $26.8 \%$ of the data variability, and the Psychological Well-Being Scale reveals $29 \%$ of the data variability.

After processing and analyzing the data, it was found that one third of the respondents in the study showed depression and anxiety on the Patient Health Scale. Differences on the scale were also revealed by demographic characteristics, according to which married students have a higher rate of depression and anxiety than married and divorced students. Impacts of depression and anxiety have also been shown by residence; in particular, students who live alone or with relatives are more likely to experience depression and anxiety than students who live with families. Statistically significant differences were also found on the Patient Health Scale according to family economic status, which showed, based on a one-dimensional analysis, that the lower the family economic status, the higher the rates of depression and anxiety among students. It is noteworthy that students with their own income have higher rates of depression and anxiety compared to students with no income of their own. Statistically significant differences were also identified with the year of study on the Patient Health Scale. In particular, the higher level a student is at, the higher his or her rates of depression and anxiety. Statistically significant was the association of academic achievement with the depression rate, according to which the higher the depression rate among students, the lower their self-assessment of success, and the lower the depression rate, the higher the students' self-assessment of their academic success.

Based on a two-dimensional analysis of the Loneliness Study Scale, it was found that almost half of the respondents had moderate to high rates of loneliness on the Loneliness Study Scale. Differences were also identified in terms of gender; in particular, female respondents were more likely to experience loneliness than males. It was found that divorced respondents experience more loneliness than single and married respondents. Students living with relatives are more likely to experience loneliness compared to students living alone or with students living alone. Differences on the Loneliness Study Scale were also revealed by family economic status, according to which the lower the students' assessment of the family's economic status, the higher their sense of loneliness, and conversely, the higher their income status, the lower their students' sense of loneliness. Also, loneliness is higher with students having their own income. Statistically significant differences were identified according to the level of learning on the loneliness scale. In particular, the lower a level the student is at, the less loneliness he or she experiences, and the higher a level the student is at, the more loneliness he or she experiences. Differences were also found between students' assessment of their own academic success 
and feelings of loneliness: the higher the feeling of loneliness, the lower the students' own assessment of their own success, and the lower the loneliness, the higher the students' assessment of their own academic success.

Based on the processing of the data obtained from the study, it was found that almost half of the students have an average rate on the Psychological Well-Being Scale, while half have a high rate. The rate of psychological well-being among female respondents is higher compared to male respondents. Also, married respondents have a higher rate on the psychological well-being scale compared to married and divorced respondents. Students, who live with family or relatives, have a higher rate of psychological well-being as opposed to students living alone. The rate of psychological well-being is lower for students who rated their family's economic status as low-income, as opposed to students who rated their family's economic status as average or high. It is also interesting to note that students with no income of their own have a higher rate of psychological well-being than those of students who have proven their own income. As for the level of learning, no statistically significant differences were found in the study. It is noteworthy, however, that statistically significant differences were found on this scale in terms of academic achievement, according to which students who rated their own academic achievement with low scores experienced lower psychological well-being, and students who rated their own academic achievement with high scores had higher psychological well-being rates.

\section{Conclusion}

In the context of the constraints induced by the COVID pandemic, the aim of the study was to establish a link between students' rates of loneliness, depression, and psychological well-being. Based on the processing of the obtained data, it was revealed that:

$>\quad$ Internal agreement rates are high for each scale;

$>\quad$ The connections between the scales used in the study are significant;

$>\quad$ One third of respondents have moderate to severe rates of depression and anxiety on the Patient Health Scale;

$>\quad$ Depression and anxiety rates are higher for students who live alone or with relatives, are at a higher level of education, value their own academic achievement with low scores, have a personal income; however, rate their family economic status as low-income one;

$>\quad$ Almost half of the respondents have average and high rates of loneliness on the Loneliness Survey Scale;

$>\quad$ Loneliness is higher with students who are divorced, living with relatives, assessing the economic situation of the family as low-income, having their own income, are the fourth-year students, and scoring their academic achievement with low points;

$>\quad$ Half of the students on the Psychological Well-Being Scale have high and almost half have average scores;

$>\quad$ Psychological well-being is high with students who are married, living with family and relatives, have no income of their own, and value the economic situation of the family as high-income. 


\section{BIBLIOGRAPHY}

1. Aaron Jarden, Positive Psychological Assessment: A practical introduction to empirically validated research tools for measuring wellbeing, "Jarden", 2011;

2. Abdur Rahman, Arunavo Bairagi, Biplob Kumar Dey \& Lailun Nahar. Loneliness and depression of university students. The Chittagong University J. of Biological Science, vol-7 (1\&2), 2012;

3. E. C Chang, Perfectionism and dimensions of psychological well-being in a college student sample: A test of a stressmediation model. Journal of Social \& Clinical Psychology, 25(9) 2006;

4. Ed Diener, Derrick Wirtz, Robert Biswas-Diener, William Tov, Chu Kim-Prieto, Dong-won Choi, and Shigehiro Oishi, New measures of well-being: Flourishing and Positive and Negative Feelings., "Springer Science+Business Media B.V”. 2009;

5. Federica Cielo, Randi Ulberg and Dina Di Giacomo. Psychological Impact of the COVID-19 Outbreak on Mental Health Outcomes among Youth: A Rapid Narrative Review. International Journal of Environmental Research and Public Health, 2021;

6. Helen Landmann and Anette Rohmann, when loneliness dimensions drift apart: Emotional, social and physical loneliness during the COVID-19 lockdown and its associations with age, personality, stress and well-being. International Journal of Psychology, 2021;

7. Hughes Mary Elizabeth, Waite Linda J, Hawkley Louise C, Cacioppo John T. A Short Scale for Measuring Loneliness in Large Surveys. "Res Aging", 2004, 26;

8. Kurt Kroenke, Robert L. Spitzer, Janet B.W. Williams, D.S.W., Bernd Lo“we. An Ultra-Brief Screening Scale for Anxiety and Depression: The PHQ-4.; Psychosomatics, 50:613-621, 2009;

9. Occupational Medicine, Patient Health Questionnaire-4, QUESTIONNAIRE REVIEW. 2016;

10. Revati K. Bhagchandani, Effect of Loneliness on the Psychological Well-Being of College Students, International Journal of Social Science and Humanity, Vol. 7, No. 1, January 2017;

11. Robert Sanders, Covid-19, social isolation and loneliness. Iriss, ESSS, 2020;

12. Sana Akhter, Psychological Well-Being in Student of Gender Difference. The International Journal of Indian Psychology Volume 2, Issue 4,2015;

13. Sheela Sundarasen, Karuthan Chinna, Kamilah Kamaludin, Mohammad Nurunnabi, Gul Mohammad Baloch, Heba Bakr Khoshaim, Syed Far Abid Hossain and Areej Sukayt. Psychological Impact of COVID-19 and Lockdown among University Students in Malaysia: Implications and Policy Recommendations. International Journal of Environmental Research and Public Health. 2020;

14. Tahira Munir, Sameera Shafiq, Zahoor Ahmad, Sarfaraz Khan, Impact of Loneliness and Academic Stress on Psychological Well Being among College Students. Academic Research International Vol. 6(2) March 2015;

15. Valeria Negovan. Dimensions of students' psychosocial well-being and their measurement: Validation of a students' Psychosocial Well Being Inventory. Europe’s Journal of Psychology 2/2010;

16. Vincenza Capone, Daniela Caso, Anna Rosa Donizzetti and Fortuna Procentese. University Student Mental WellBeing during COVID-19 Outbreak: What Are the Relationships between Information Seeking, Perceived Risk and Personal Resources Related to the Academic Context? "SustainabiliTy, MDPI", 2020. 